\title{
Questionnaire for Assessment of Clinical Supervision Strategies in Nursing: Construction and Validation of the Qacssn
}

\author{
Inês Rocha*, Margarida Reis Santos, Regina Pires \\ Hospital in Porto, Portugal
}

Copyright $\bigcirc 2017$ by authors, all rights reserved. Authors agree that this article remains permanently open access under the terms of the Creative Commons Attribution License 4.0 International License

\begin{abstract}
Purpose: The purpose of the study was to construct and validate a questionnaire that assesses the frequency with which the Clinical Supervision (CS) strategies are implemented and the frequency with which the nurses want them to be implemented in their services. Design: The research is carried out under a quantitative paradigm, of the descriptive and exploratory type, and of a transversal nature. The non-probabilistic sample comprised 273 nurses. The data was collected by applying the Questionnaire for Assessment of Clinical Supervision Strategies in Nursing (QACSSN), between May and September 2012. Methods: A descriptive statistical analysis was made of the data obtained. The content collected from the QACSSN was validated by a group of 11 experts. Cronbach's alpha coefficient was also ascertained. Findings: The results show the experts agree with the inclusion of the 16 CS strategies in the QACSSN. The QACSSN has good internal consistency indices, both in terms of the frequency of implementation of the CS strategies and concerning the level of desire for their implementation. Conclusions: The QACSSN is a reliable instrument with valid content, and therefore can be used in the context of Mentorship, Preceptorship or CS. Clinical Relevance: The study contributes to improved quality of care by identifying the most appropriate CS strategies for the process of supervision in health contexts, enabling the nurses to play an active role in this process.
\end{abstract}

Keywords Supervision, Nursing, Quality of Health Care, Job Satisfaction

\section{Introduction}

CS is an area which has been developed to enable nurses to enhance their knowledge and skills, both on a personal and professional level, which are essential in autonomous decision making (Winstanley \& White, 2003; Koivu, Saarinen, \& Hyrkäs, 2011; Fowler, 2013). It is important to establish measures that promote the well-being of and quality of practices for clients (Cho, Laschinger, \& Wong, 2006; Cruz, Carvalho, \& Sousa, 2012), with a view to their protection and the safety of the care (Winstanley \& White, 2003; Brunero \& Stein-Parbury, 2008; Dilworth, Higgins, Parker, Kelly, \& Turner, 2013). CS arises as a response to the implementation of a high-quality nursing practice, given that the very process of supervision leads to the questioning of nursing interventions, aimed at improving the care offered to the community (Hyrkäs \& Shoemaker, 2007; Butterworth, Bell, Jackson, \& Pajnkihar, 2008; Koivu, Hyrkäs, \& Saarinen, 2011; Fowler, 2014).

The supervisory process should include the development of skills, providing support, and personal and professional encouragement to nurses (Francke \& Graaff, 2012). It can be applied in the context of supervision of students (Mentorship), in professional induction (Preceptorship) or in the supervision of professionals (CS) (Newton, 2013). As such, the clinical supervisor should implement dynamic and individualised CS strategies aimed at boosting the development of each nurse (Severinsson \& Sand, 2010; McColgan \& Rice, 2012).

It is pertinent to learn about the nurses' perception in relation to the frequency and desired implementation of CS strategies in their practices, since this enables well-defined CS policies to be successfully implemented. Since no scientific evidence that explores the aforesaid aspects has been found, it was considered relevant to conduct a study to investigate this issue.

\section{Purpose and Objectives}

The purpose of the study was to construct and validate a questionnaire that assesses the frequency with which the CS strategies are implemented and the frequency with which the 
nurses want them to be implemented in their services. The specific objectives of the research were as follows: identification of the CS strategies that are considered most relevant to nursing; construction of a questionnaire to assess the frequency of implementation of CS strategies; construction of a questionnaire to assess the frequency with which the nurses want the CS strategies to be implemented; validation of the content and reliability of the constructed questionnaire.

\section{Methodology}

The choice of a quantitative paradigm is backed up by the notions defended by Winstanley \& White (2003), who argue that the creation of instruments to assess the efficiency of CS is peremptory, and that it is essential to conduct more quantitative research in this area.

The methodological approach involved the following stages: construction of the QACSSN; assessment of the validity of the QACSSN content; determination of the reliability of the QACSSN.

The study involved the participation of 273 nurses from various hospitals and primary health care (PHC) services and institutions of the different regions of Portugal. The nurses were aged between 24 and 58 years old ( $M=34$ years; $\mathrm{SD}=7.05$ year) and their nursing experience varied from 1 to 36 years $(\mathrm{M}=11$ years; $\mathrm{SD}=6.77$ years $)$. The majority of the participants $(83.2 \% ; n=227)$ were female, $64.3 \%(n=175)$ worked in a hospital and $35.7 \%(n=97)$ in PHC.

\section{Construction of the QACSSN}

Since the research carried out did not find any instrument that could meet the defined purpose and objectives, a review was made of the available literature on CS strategies, resulting in 16 strategies selected to be included in the QACSSN: individual supervision sessions; group supervision sessions; feedback; critical-reflective analysis of practices; case analysis with the supervised person; case analysis in a group; self-supervision; analysis of documentation on nursing care; demonstration; reflective report; remote supervision: telephone; remote supervision: e-mail; remote supervision: skype ${ }^{\circledR}$; support; continuous training; observation.

The questionnaire is split into two parts: the first part has 20 questions aimed at finding out the participant's profile and the second part, comprising $16 \mathrm{CS}$ strategies, aims to collect data about the nurses' opinion on the frequency of implementation of the strategies and the desired frequency of their implementation. Based on the literature relative to the frequency of implementation of the CS strategies in health services, the following order was established for the multiple choice questions: 1-once or more times a day; 2-once or more times a week; 3-once or more times a month; 4-more than once a quarter; and 5-never.

A draft questionnaire was drawn up which was submitted to the appraisal of international and national experts. The group of international experts comprised four nursing teachers with clinical experience who had worked in the area of CS, from the United Kingdom, Ireland, Germany and Finland, who were contacted by e-mail. Regarding the national experts, six were nursing teachers with clinical experience and research carried out in the area of CS, and one was an education science teacher. They were asked to conduct an idiomatic, conceptual and semantic validation of the questionnaire. Table 1 lists the alterations suggested by the experts, which were taken into consideration for the preparation of the QACSSN.

Table 1. Alterations suggested by the experts

\begin{tabular}{|c|c|}
\hline Experts & Alterations suggested \\
\hline International & $\begin{array}{l}\text { The «never» answer option should be placed last in } \\
\text { multiple choice questions. }\end{array}$ \\
\hline Nacional & $\begin{array}{l}\text { In addition to what the international experts } \\
\text { mention, they also suggested: } \\
\text { - } \quad \text { replace the strategy «critical-reflexive } \\
\text { questioning» for «critical-reflexive analysis of } \\
\text { practices»; } \\
\text { - replace the «professional portfolio» strategy } \\
\text { for «reflective report»; } \\
\text { - } \quad \text { include in the words «remote supervision» } \\
\text { before e-mail, telephone and skype } \AA ; \\
\text { - } \\
\text { not include the «practice reflection» strategy } \\
\text { in the questionnaire. }\end{array}$ \\
\hline
\end{tabular}

The pre-test of the questionnaire was conducted on 19 nurses, 10 without training in CS and 9 with training in CS. No alterations to the questionnaire were suggested.

\section{Assessment of the Validity of the QACSSN Content}

According to Polit \& Beck (2010), content validity is a process of judgement made up of two distinctive parts: the first involves the development of the instrument and the second its assessment through analysis by specialists.

Content validity is defined through bibliographic research and consultation with scholars from the field in question and representatives of the population of interest (DeVon et al., 2007), thus the development of the instrument covers three phases: the identification of domains, the formation of items and the construction of the instrument (Polit \& Beck, 2010). The aspects referred to above were considered during the construction of the QACSSN, therefore the first part of the judgement of the content validity was carried out.

The second part was carried out through the group of international and national experts and by the group of nurses who participated in the pre-test. The group of experts analysed the first version of the QACSSN (prepared based on the literature review) with the objective of judging the validity of its content. Taking into consideration the 
proposed suggestions, a second version of the QACSSN was prepared which was submitted to pre-testing in order to assess the perception of the nurses (representative of the population) with respect to the items comprising the questionnaire.

Having conducted both parts of the content validity judgement recommended by Polit \& Beck (2010), it is considered that the QACSSN has content validity.

\section{Determination of the Reliability of the QACSSN}

The reliability of the QACSSN was estimated through the determination of its internal consistency by calculating
Cronbach's alpha coefficient, whereby it is considered that in order for an instrument to have good internal consistency the value should be greater than 0.80 (Pallant, 2010).

Table 2 presents the Cronbach alpha values for the implementation frequency of the $16 \mathrm{CS}$ strategies in the QACSSN. As can be seen, all the strategies obtained a Cronbach alpha value above 0.90 , demonstrating the good internal consistency of the instrument.

Table 3 presents the Cronbach alpha values for frequency relative to the desired implementation of the $16 \mathrm{CS}$ strategies in the QACSSN. Values above 0.90 were also obtained, once again demonstrating the good internal consistency of the QACSSN.

Table 2. Internal consistency measures of the QACSSN for the frequency of implementation of clinical supervision strategies

\begin{tabular}{|c|c|c|c|}
\hline Clinical Supervision Strategies & M & $r$ & $\alpha$ \\
\hline Individual supervision sessions & 49,89 & 0,720 & 0,915 \\
\hline Group supervision sessions & 49,57 & 0,633 & 0,917 \\
\hline Feedback & 49,93 & 0,760 & 0,913 \\
\hline Critical-reflective analysis of practices & 50,07 & 0,720 & 0,915 \\
\hline Case analysis with the supervised person & 49,87 & 0,755 & 0,914 \\
\hline Case analysis in a group & 49,49 & 0,544 & 0,919 \\
\hline Self-supervision & 50,35 & 0,446 & 0,922 \\
\hline Analysis of documentation on nursing care & 50,11 & 0,690 & 0,915 \\
\hline Demonstration & 50,34 & 0,781 & 0,912 \\
\hline Reflective report & 49,12 & 0,669 & 0,917 \\
\hline Remote supervision: telephone & 48,90 & 0,393 & 0,924 \\
\hline Remote supervision: e-mail & 49,00 & 0,492 & 0,921 \\
\hline Remote supervision: skype ${ }^{\circledR}$ & 48,58 & 0,406 & 0,923 \\
\hline Support & 50,14 & 0,713 & 0,915 \\
\hline Continuous training & 49,79 & 0,557 & 0,919 \\
\hline Observation & 50,45 & 0,703 & 0,915 \\
\hline Cronbach's Alpha Total & \multicolumn{3}{|c|}{0,922} \\
\hline
\end{tabular}

M - Mean; $r$ - Item-total correlation; $\alpha$ - Cronbach's alpha excluding item

Table 3. Internal consistency measures of the QACSSN for the frequency related to the desire to implement clinical supervision strategies

\begin{tabular}{|c|c|c|c|}
\hline Clinical Supervision Strategies & M & $r$ & $\alpha$ \\
\hline Individual supervision sessions & 39,95 & 0,622 & 0,907 \\
\hline Group supervision sessions & 39,75 & 0,711 & 0,905 \\
\hline Feedback & 39,99 & 0,743 & 0,904 \\
\hline Critical-reflective analysis of practices & 40,13 & 0,662 & 0,906 \\
\hline Case analysis with the supervised person & 39,90 & 0,671 & 0,906 \\
\hline Case analysis in a group & 39,61 & 0,634 & 0,907 \\
\hline Self-supervision & 40,26 & 0,560 & 0,909 \\
\hline Analysis of documentation on nursing care & 40,06 & 0,675 & 0,906 \\
\hline Demonstration & 40,27 & 0,738 & 0,903 \\
\hline Reflective report & 39,11 & 0,556 & 0,909 \\
\hline Remote supervision: telephone & 38,93 & 0,402 & 0,915 \\
\hline Remote supervision: e-mail & 39,25 & 0,485 & 0,912 \\
\hline Remote supervision: skype $^{\circledR}$ & 38,66 & 0,312 & 0,918 \\
\hline Support & 40,23 & 0,718 & 0,904 \\
\hline Continuous training & 39,67 & 0,570 & 0,909 \\
\hline Observation & 40,24 & 0,722 & 0,904 \\
\hline Cronbach's Alpha Total & \multicolumn{3}{|c|}{0,913} \\
\hline
\end{tabular}

$\mathrm{M}$ - Mean; $\mathrm{r}$ - Item-total correlation; $\alpha$ - Cronbach's alpha excluding item 
A total Cronbach alpha value of 0.922 was obtained for the actual frequency of the strategies, and for the desired frequency of the strategies the value obtained was 0.913 . The fact that both of the Cronbach alpha values obtained are above 0.80 indicates that there is good internal consistency (Pallant, 2010), hence it is concluded that the QACSSN is reliable.

\section{Conclusions}

The QACSSN intends to contribute to the enrichment of validated measurement instruments in the CS area, and may be used when implementing/assessing the efficiency of CS programmes in health contexts.

This questionnaire could be useful in future research to obtain data on CS strategies, namely as an instrument which enables CS needs to be diagnosed in a particular context. Its application can allow one to observe which CS strategies are most frequently implemented and which CS strategies the nurses would like to see implemented more frequently; and this data could be used as a basis for planning an appropriate CS programme for a given context. A CS programme focused on the real needs of a context and which includes the CS strategies suggested by the nurses themselves could also benefit from fact that these nurses would be motivated towards their implementation.

Although the QACSSN was drawn up from the CS perspective, we believe it could also be used in the context of Mentorship and Preceptorship, to help prepare solid supervisory programmes which support decision making, aimed at improving results, minimising risks and enhancing the efficiency of nursing care.

\section{REFERENCES}

[1] Brunero, S. \& Stein-Parbury, J. (2008). The effectiveness of clinical supervision in nursing: an evidenced based literature review. Australian Journal of Advanced Nursing, 25(3), 86-94.

[2] Butterworth, T.; Bell, L.; Jackson, C. \& Pajnkihar, M. (2008). Wicked spell or magic bullet? A review of the clinical supervision literature 2001-2007. Nurse Education Today, 28, 264-272.

[3] Cho, J.; Laschinger, H. \& Wong, C. (2006). Workplace empowerment, work engagement and organizational commitment of new graduate nurses. Canadian Journal of
Nursing Leadership, 19(3), 43-60.

[4] Cruz, S.; Carvalho, L. \& Sousa, P. (2012). Clinical supervision in nursing: the (un)known phenomenon. Procedia-Social and Behavioral Sciences, 69, 864-873.

[5] Devon, H. [et al.] (2007). A psychometric toolbox for testing validity and reliability. Journal of Nursing Scholarship, 39(2), 155-164.

[6] Dilworth, S.; Higgins, I.; Parker, V.; Kelly, B. \& Turner, J. (2013). Finding a way forward: a literature review on the current debates around clinical supervision. Contemporary Nurse, 45(1), 22-32.

[7] Fowler, J. (2013). Clinical supervision: from staff nurse to nurse consultant. Part 10: prioritizing and making time. British Journal of Nursing, 22(22), 1322.

[8] Fowler, J. (2014). Clinical supervision: from staff nurse to nurse consultant. Part 12: series summary. British Journal of Nursing, 23(2), 114.

[9] Francke, A. \& Graaff, F. (2012). The effects of group supervision of nurses: a systematic literature review. International Journal of Nursing Studies, 49(9), 1165-1179.

[10] Hyrkäs, K. \& Shoemaker, M. (2007). Changes in the preceptor role: re-visiting preceptors' perceptions of benefits, rewards, support and commitment to the role. Journal of Advanced Nursing, 60(5), 513-524.

[11] Koivu, A; Hyrkäs, K. \& Saarinen, P. (2011). Who attends clinical supervision? The uptake of clinical supervision by hospital nurses. Journal of Nursing Management, 19 (5), 69-79.

[12] Koivu, A; Saarinen, P. \& Hyrkäs, K. (2011). Stress relief of practice development: varied reasons for attending clinical supervision. Journal of Nursing Management, 19(1), 644-654.

[13] McColgan, K. \& Rice, C. (2012). An online training resource for clinical supervision. Nursing Standard, 26(24), 35-39.

[14] Newton, S. (2013). Clinical supervision policy: version $n^{\circ} 2: 3$. Plymouth: National Health Service Plymouth.

[15] Pallant, J. (2010). SPSS: survival manual (4 ${ }^{\text {th }}$ ed.). Berkshire: McGraw-Hill Companies.

[16] Polit, D. \& Beck, C. (2010). Essentials of nursing research: appraising evidence for nursing practice ( $7^{\text {th }}$ ed.). Philadelphia: Wolters Kluwer.

[17] Severisson, E. \& Sand, Ǎ. (2010). Evaluation of the Clinical Supervision and Professional Development of Student Nurses. Journal of Nursing Management, 18, 669-677.

[18] Winstanley, J. \& White, E. (2003). Clinical supervision: models, measures and best practice. Nurse Researcher, 10 (4), 7-38. 